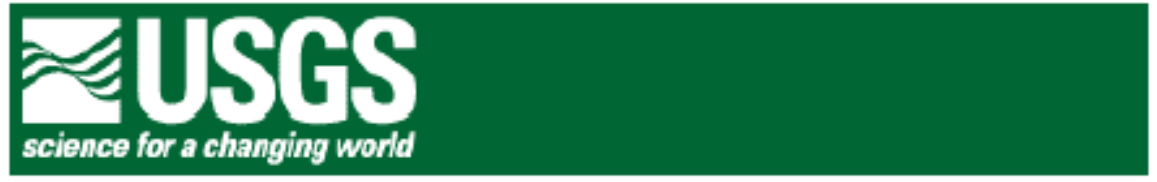

\title{
Application of Magnetic and Electromagnetic Methods to Locate Buried Metal
}

By Robert J. Horton

This report is preliminary and has not been reviewed for conformity with U.S. Geological Survey editorial standards and stratigraphic nomenclature. Any use of trade, product, or firm names is for descriptive purposes only and does not imply endorsement by the U.S. Government.

Open-File Report 03-317 2003

U.S. Department of the Interior

U.S. Geological Survey 


\section{Application of Magnetic and Electromagnetic Methods to Locate Buried Metal USGS Open-File Report 03-317}

By Robert J. Horton

To remediate environmental problems related to hazardous waste sites, knowledge of the distribution of buried materials is essential. Geophysical surveys provide a rapid, noninvasive means of characterizing the distribution of buried metal in landfills. The U.S. Geological Survey has experience in conducting, processing, and interpreting geophysical surveys for the characterization of such sites, and can provide assistance in the design of such surveys.

The USGS conducted a geophysical survey to locate buried metallic objects (steel drums) within a landfill on the U.S. Air Force Academy grounds near Colorado Springs, CO. Magnetic and electromagnetic (EM) methods were chosen to survey the landfill because they easily detect magnetic and conductive objects buried at shallow depths.

Magnetic methods respond to ferromagnetic materials and can detect metallic objects composed of iron and steel. At the USAF Academy, the vertical gradient of the magnetic field was measured. Vertical gradient measurements are more sensitive to small magnetic targets and typically have better anomaly resolution than total field magnetic measurements.

EM methods respond to the electrical conductivity of the ground and can detect objects composed of conductive metals such as iron, steel, copper, and aluminum. EM measurements provide information about the location, depth and shape of conductive objects. EM methods can also detect subsurface contaminant plumes produced by conductive fluids leaking from buried containers.

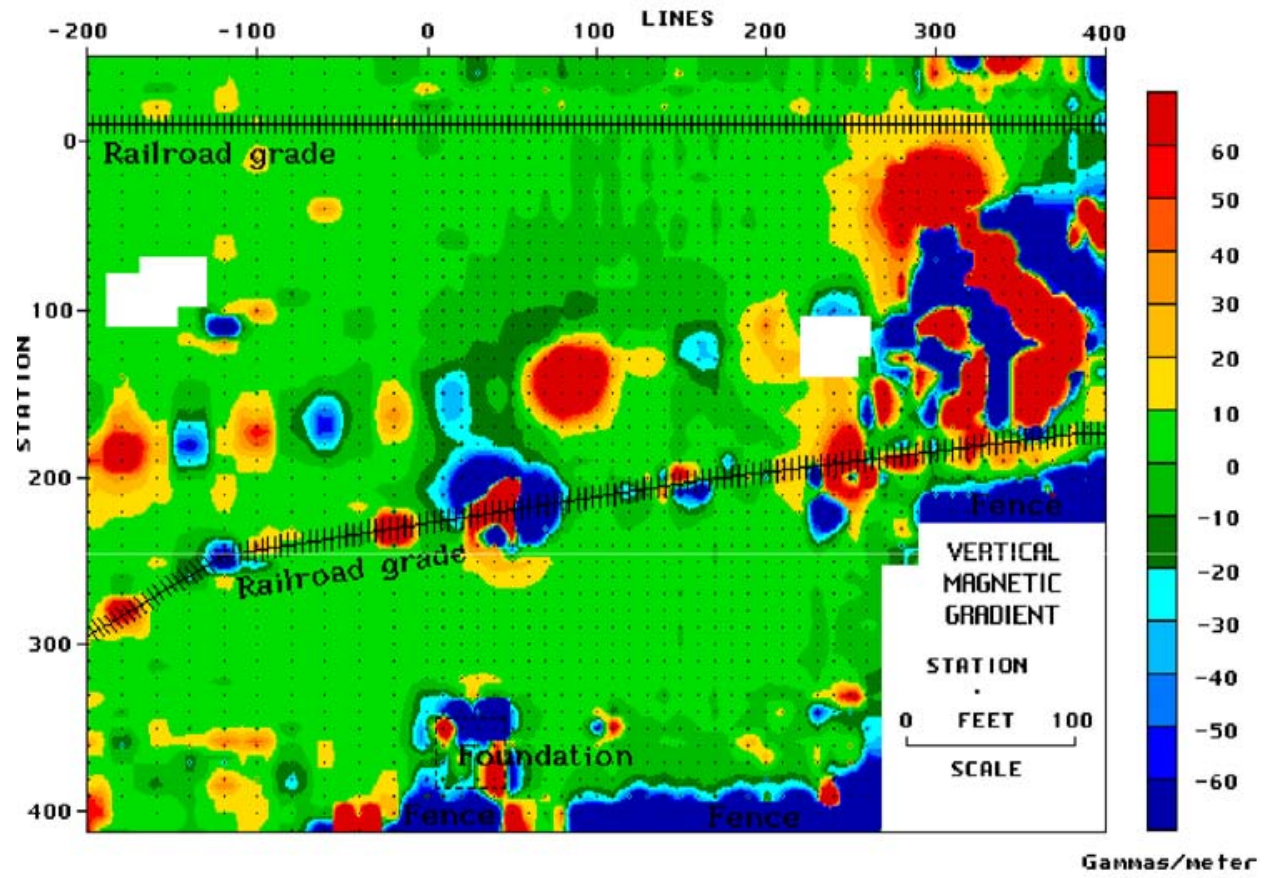

Figure 1. Vertical magnetic gradient map showing the distribution of buried metal objects in the landfill. Red, yellow and blue areas are magnetic anomalies produced by iron and steel objects. Green areas are free of ferromagnetic objects. No data were collected in the white areas. 
The geophysical survey at the USAF Academy identified many magnetic and conductive anomalies that show the distribution of buried metallic objects in the landfill. A large area containing buried magnetic material is located in the eastern part of the survey area (fig. 1). The observed magnetic anomalies indicate the presence of both large and small buried metallic objects.

The EM survey (fig. 2) identified two linear conducting anomalies striking across the landfill. Depth analysis indicates these conductors are buried less than 6 feet deep. These linear conductive features are believed to be caused by buried pipes, cables, or fencing. The geophysical surveys also showed that large areas of the landfill have no magnetic or conductive anomalies and therefore must be relatively free of buried metal. For more information about environmental applications of magnetic and EM methods see Ward (1990). To find more about the USAF Academy survey see Horton and others (1993).

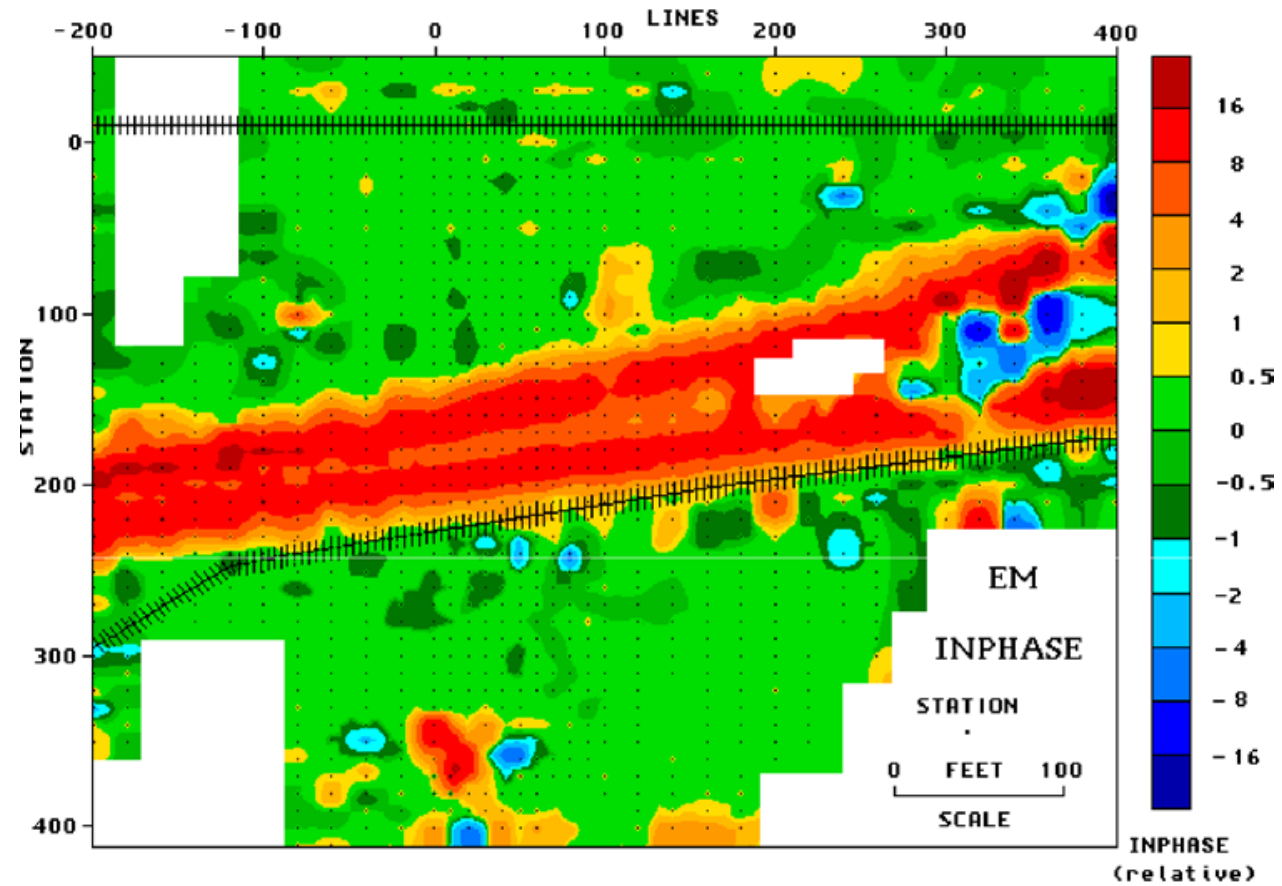

Figure 2. Electromagnetic map showing the distribution of conductive objects in the land fill. Red, orange and blue areas are conductive anomalies produced by buried metal. Green areas represent are free of conductive objects. No data were collected in white areas.

\section{References}

Horton, R.J., Busby, J.W., Knoshaug, R.N., and Powers, M.H., 1993, Landfill mapping using multi-disciplinary geophysical techniques at the U.S. Air Force Academy, Colorado Springs, CO: in proceedings of the Symposium on the Application of Geophysics to Engineering and Environmental Problems, pp. 109-128.

Ward, S.H., 1990, Geotechnical and Environmental Geophysics, Volume I: Society of Exploration Geophysicists, Investigations in Geophysics, no. 5, 387p. 